\title{
A study of lipid parameters among GDM and non GDM pregnant women: a hospital based study
}

\author{
Bharathi K. R., Vijayalakshmi S., Shrunga R. P.*
}

\begin{abstract}
Department of Obstetrics and Gynecology, Adichunchanagiri Institute of Medical Sciences, Bellur, Mandya,
\end{abstract} Karnataka, India

Received: 26 September 2017

Accepted: 30 October 2017

\author{
*Correspondence: \\ Dr. Shrunga R. P., \\ E-mail: shrunga.mims@gmail.com
}

Copyright: (c) the author(s), publisher and licensee Medip Academy. This is an open-access article distributed under the terms of the Creative Commons Attribution Non-Commercial License, which permits unrestricted non-commercial use, distribution, and reproduction in any medium, provided the original work is properly cited.

\begin{abstract}
Background: Altered maternal lipid metabolism is common in pregnancy. In women with GDM physiological changes in insulin and lipid levels are exaggerated during pregnancy, leading to significant alterations in lipid levels compared to normal pregnancy. Assessment of raise in certain lipid parameters in pregnant women with GDM and non GDM.

Methods: A hospital based case control study done in the Department of OBG AIMS Bellur, Mandya, Karnataka, with sample size of 100 pregnant women. 50 cases of GDM (confirmed by OGCT) and 50 controls (non GDM cases) pregnant women were taken during 1 year study period from June 2015 to June 2016. Mean age of presentation of women was 20-25 yrs. Ethical committee clearance was taken and consent from control and cases was taken. Fasting lipid profile was sent. Parameters obtained were analyzed using student $\mathrm{t}$ test for statistical significance.

Results: There was no statistical difference in age and parity between control and case group. Triglyceride (cases$286.4 \pm 77.60 \mathrm{mg} / \mathrm{dl}) \quad($ controls $-166 \pm 26 \mathrm{mg} / \mathrm{dl}$ ), total cholesterol (cases-256.5 $\pm 41.7 \mathrm{mg} / \mathrm{dl})$ (controls $202.5 \pm 20.18 \mathrm{mg} / \mathrm{dl}$ ), VLDL (cases-53.4 $\pm 13.2 \mathrm{mg} / \mathrm{dl}$ ) (controls-46.6 $\pm 13.1 \mathrm{mg} / \mathrm{dl}$ ) showed statistically significant values ( $\mathrm{p}$ value $<0.001$ ). HDL and LDL values did not show any statistical significance ( $\mathrm{p}$ value $>0.5$ ) among GDM and non GDM group. Lipid profile was performed predominately in women in II trimester.

Conclusions: Serum triglyceride, total cholesterol and VLDL level are significantly higher among woman with GDM compared to non GDM pregnant women, where in the lipid profile can be used as predictor for gestational diabetes mellitus in future which needs further research.
\end{abstract}

Keywords: GDM, Lipid parameters, Non GDM, Serum triglyceride, Total cholesterol, VLDL

\section{INTRODUCTION}

Altered maternal lipid metabolism is common in pregnancy. In women with GDM physiological changes in insulin and lipid levels are exaggerated during pregnancy, leading to significant alterations in lipid levels compared to normal pregnancy. Gestational diabetes mellitus (GDM), defined as glucose intolerance first diagnosed during pregnancy, is increasing in prevalence worldwide. ${ }^{1}$ Up to $22 \%$ of all pregnancies are affected by GDM, and this prevalence may be higher under new diagnostic criteria. $^{2}$ Physiological insulin resistance underlies all pregnancies beginning around 24-28 weeks of gestation and progressing through the third trimester. Altered maternal lipid metabolism is also common in pregnancy with modest increases in lipids early in pregnancy and significant elevations of lipids later in pregnancy, specifically, triglycerides and to a lesser extent phospholipids and cholesterol. ${ }^{3,4}$ In women with GDM, the physiological changes in insulin and lipids are exaggerated and may indicate underlying metabolic dysfunction that transiently manifests during pregnancy. ${ }^{5}$ 
Circulating lipid patterns in GDM versus normal pregnancy have been extensively studied, with most studies observing higher triglyceride levels across all trimesters of pregnancy in women with GDM. ${ }^{3}$ Hormonal changes during pregnancy such as increased levels of progesterone, cortisol, oestrodiol and human chorionic somatomammotropin (hCS) mediate insulin resistance. ${ }^{6}$ Various studies in different parts of the world have strongly indicated that lipid metabolism during pregnancy may have a role to play in the aetiology and pathogenesis of GDM. This study is conducted with the aim of studying lipid parameters in GDM and non GDM patients.

\section{METHODS}

A hospital based case control study. Conducted in the Department of OBG AIMS Bellur, Mandya, Karnataka. Sample size of 100 pregnant women presenting to the OBG OPD were taken. Study period of one year from June 2015 to June 2016. Ethical committee clearance was taken and consent from control and cases was taken. Mean age of presentation of women both with GDM and non GDM women were 20-25 yrs. 50 cases of GDM are included in cases group and 50 cases of non GDM pregnant women were taken as control group. All pregnant women attending the OPD were offered OGCT with 75 grams of glucose. Glucose load was administered irrespective of the last meal, and plasma glucose was measured one hour later. Cut off value of $140 \mathrm{mg} / \mathrm{dl}$ was taken into consideration. All pregnant women with impaired OGCT were offered OGTT for confirmation by using 100 grams OGTT with Carpenter and Couston Criteria. Fasting lipid profile was sent for the hospital laboratory, for both controls and cases, predominately of women in $2^{\text {nd }}$ trimester. Fasting lipid profile parameters were analysed by Tinder's methods and reported. The results thus obtained were analyzed using student ' $t$ ' test for statistical significance using SPSS version 20 .

\section{RESULTS}

During the study period of one year, 50 GDM patients were taken as cases and 50 non GDM women with normal OGCT were taken as controls. There was no statistically significant difference in age and parity between the two groups. GDM women diagnosed in 2nd trimester. Fasting lipid parameters obtained were analyzed to obtain the results. Parameters are serum total cholesterol, triglyceride, HDL, LDL, VLDL. For obtaining the lipid parameters Tinder's method was used. $\mathrm{p}$ value obtained for all the lipid parameters and statistical significance is analyzed using SPSS version 20. Serum total cholesterol (cases $-256.5 \pm 41.7 \mathrm{mg} / \mathrm{dl}$ ), (controls $202.5 \pm 20.18 \mathrm{mg} / \mathrm{dl})$ ( $\mathrm{p}$ value $<0.001)$; serum triglyceride (cases $-286.5 \pm 77.60 \mathrm{mg} / \mathrm{dl})$, (controls $166 \pm 26 \mathrm{mg} / \mathrm{dl})(\mathrm{p}$ value $-<0.001$ ); serum VLDL level (cases$53.4 \pm 13.2 \mathrm{mg} / \mathrm{dl}$ ) (controls $-46.6 \pm 13.1 \mathrm{mg} / \mathrm{dl}$ ) (p value $<0.001$ ) were significantly higher in women with GDM as compared with controls. In contrast serum HDL, LDL, did not show any difference between GDM and control pregnancies.

Table 1: Values of lipid parameters among GDM and non GDM women.

\begin{tabular}{|llll|}
\hline Lipid parameters & $\begin{array}{l}\text { GDM } \\
\text { women } \\
\text { (cases) }\end{array}$ & $\begin{array}{l}\text { Non GDM } \\
\text { women } \\
\text { (controls) }\end{array}$ & $\begin{array}{l}\text { P } \\
\text { value }\end{array}$ \\
\hline $\begin{array}{l}\text { Total cholesterol } \\
\text { (mg/dl) }\end{array}$ & $256.5 \pm 41.7$ & $202.5 \pm 20.18$ & $<0.001$ \\
\hline Triglyceride (mg/dl) & $286.4 \pm 77.60$ & $166 \pm 26$ & $<0.001$ \\
\hline HDL (mg/dl) & $44.3 \pm 6.8$ & $45.3 \pm 8$ & 0.5 \\
\hline LDL (mg/dl) & $123.3 \pm 24.7$ & $126 \pm 24.8$ & 0.3 \\
\hline VLDL (mg/dl) & $53.4 \pm 13.2$ & $46.6 \pm 13.1$ & $<0.001$ \\
\hline
\end{tabular}

Table 1 revealed an average serum total cholesterol of $256.7 \mathrm{mg} / \mathrm{dl}$ in GDM cases and $202.5 \mathrm{mg} / \mathrm{dl}$ in control group. On statistical analysis, it showed a 'p' value of $<0.001$, which is statistically significant, indicating that the raise of total cholesterol among GDM compared to the non GDM women.

Table 1 presented an average serum trigyceride of $286.4 \mathrm{mg} / \mathrm{dl}$ in GDM cases and $166 \mathrm{mg} / \mathrm{dl}$ in control group. On statistical analysis, it showed a ' $p$ ' value of $<0.001$, which is statistically significant, indicating that the raise of total cholesterol among GDM compared to the non GDM women.

Table 1 showed an average serum VLDL of $53.4 \mathrm{mg} / \mathrm{dl}$ in GDM cases and $46.6 \mathrm{mg} / \mathrm{dl}$ in control group. On statistical analysis, it showed a 'p' value of $<0.001$, which is statistically significant, indicating that the raise of total cholesterol among GDM compared to the non GDM women.

Table 1 revealed an average serum HDL of $44.3 \mathrm{mg} / \mathrm{dl}$ in GDM cases and $45.3 \mathrm{mg} / \mathrm{dl}$ in control group. On statistical analysis, it showed a ' $p$ ' value of 0.5 , which is statistically insignificant. It also showed an average serum LDL of $123.3 \mathrm{mg} / \mathrm{dl}$ in GDM cases and $46.6 \mathrm{mg} / \mathrm{dl}$ in control group which on analysis showed a ' $p$ ' value of 0.3 , which is not statistically significant.

\section{DISCUSSION}

Gestational diabetes mellitus is a complex condition that manifests as insulin resistance first diagnosed during pregnancy. ${ }^{7}$ Women with GDM are at significantly increased risk of developing metabolic dysfunction after pregnancy including hyperlipidaemia. ${ }^{8}$ Although many studies suggest that women with GDM have increased levels of triglycerides, LDL-C and total cholesterol and lower levels of HDL-C, these findings are generally inconsistent. ${ }^{3}$ Alterations in maternal lipid metabolism are a normal part of pregnancy with an early accumulation of lipids in maternal tissue and the development of hyperlipidaemia in the latter half of pregnancy. ${ }^{4}$ Early in pregnancy, fat accumulation occurs 
due to increased lipid synthesis and hyperphagia; in the last trimester of pregnancy, fat accumulation halts due to decreased adipose tissue lipoprotein lipase activity. As a consequence of reduced lipoprotein lipase activity, hyperlipidemia, mainly marked by elevated triglyceride levels, is observed towards the end of pregnancy. Hypertriglyceridemia is thought to be one of the key drivers of fetal macrosomia. Accumulation of increasing free fatty acid levels due to increased adipose tissue may be a mechanism for markedly increased first-trimester triglyceride levels in women with GDM as increased free fatty acids can worsen insulin resistance. ${ }^{9}$ Present study shows that triglycerides, total cholesterol, VLDL levels are significantly elevated among GDM women compared with women without insulin resistance. This study was not able to account for other potential sources of confounding such as race/ethnicity, genetic risk for GDM, smoking, and other socio demographic risks because of lack of information. Alterations in maternal lipid metabolism are a normal part of pregnancy with an early accumulation of lipids in maternal tissue and the development of hyperlipidemia in the latter half of pregnancy. As a consequence of reduced lipoprotein lipase activity, hyperlipidemia, mainly marked by elevated triglyceride levels, is observed. Present finding of consistent elevations in triglyceride levels throughout pregnancy in women with GDM compared with those without insulin resistance is important as hypertriglyceridemia. Triglycerides are elevated early in pregnancy with the greatest difference in levels between women with and without GDM occurring during the second trimester when GDM is traditionally diagnosed. Although cannot determine from this study causal relationships between triglyceride levels and GDM, it is apparent that triglycerides are elevated early in pregnancy while other lipid subtypes are not, and, therefore, are also probably not elevated pre pregnancy in women with GDM compared with those without insulin resistance. Although several studies have suggested that lipid patterns may be used to identify women at risk for developing GDM coupling triglyceride measurements with other markers of oxidative stress and insulin resistance such as cytokines, glucose and essential fatty acids, may provide useful diagnostic criteria for identifying women at risk for developing GDM. Other studies showing correlation to our study are Asare-anane $\mathrm{H}$ et al, Ryckman et al showing similar results as that of present study. ${ }^{10,11}$

\section{CONCLUSION}

Serum triglyceride, total cholesterol and VLDL level are significantly higher among woman with GDM compared to non GDM pregnant women, where in the lipid profile can be used as predictor for gestational diabetes mellitus in future which needs further research.

Funding: No funding sources

Conflict of interest: None declared

Ethical approval: The study was approved by the Institutional Ethics Committee

\section{REFERENCES}

1. Ferrara A. Increasing prevalence of gestational diabetes mellitus: a public health perspective. Diabetes Care. 2007;30 (Suppl 2):141-6.

2. Jenum AK, Morkrid K, Sletner L, Vangen S, Torper JL, Nakstad B, et al. Impact of ethnicity on gestational diabetes identified with the WHO and the modified International Association of Diabetes and Pregnancy Study Groups criteria: a population-based cohort study. Eur J Endocrinol. 2012;166:317-24.

3. Herrera E, Ortega-Senovilla H. Disturbances in lipid metabolism in diabetic pregnancy: are these the cause of the problem? Best Pract Res Clin Endocrinol Metab. 2010;24:515-25.

4. Alvarez JJ, Montelongo A, Iglesias A, Lasuncion MA, Herrera E. Longitudinal study on lipoprotein profile, high density lipoprotein subclass, and postheparin lipases during gestation in women. J Lipid Res. 1996;37:299-308.

5. Carpenter MW. Gestational diabetes, pregnancy hypertension, and late vascular disease. Diabetes Care 2007;30 (Suppl 2):246-50.

6. Carr DB, Gabbe S. Gestational diabetes: detection, management, and implications. Clin Diabetes. 1998;16(1):4.

7. American Diabetes A. Diagnosis and classification of diabetes mellitus. Diabetes Care. 2014;37(Suppl 1):8190.

8. Warth MR, Knopp RH. Lipid metabolism in pregnancy. Interactions of diabetes, body weight, age, and high carbohydrate diet. Diabetes 1977;26:1056-62.

9. vandeWoestijne AP, Monajemi $H$, Kalkhoven E, Visseren FLJ. Adipose tissue dysfunction and hypertriglyceridemia: mechanisms and management. Obes Rev. 2011;12:829-40.

10. Asare-Anane H, Bawah AT, Osa-Andrews B, Adanu R, Ofori EK, Tagoe SB, Nyarko AK. Lipid Profile In Ghanaian Women With Gestational Diabetes Mellitus. Int J Scient Tec Res. 2013 Apr 25;2(4):168-75.

11. Ryckman KK, Spracklen CN, Smith CJ, Robinson JG, Saftlas AF. Maternal lipid levels during pregnancy and gestational diabetes: a systematic review and metaanalysis. BJOG. 2015;122:643-651.

Cite this article as: Bharathi KR, Vijayalakshmi S, Shrunga RP. A study of lipid parameters among GDM and non GDM pregnant women: a hospital based study. Int J Reprod Contracept Obstet Gynecol 2017;6:5488-90. 